\title{
Use of first principles and Thermo-Calc to identify potential low elastic modulus titanium-based alloys for biomedical applications
}

\author{
MN Madigoe ${ }^{\mathrm{a}, \mathrm{b},{ }^{*}}$, R Modiba $^{\mathrm{a}, 1}$ and LA Cornish ${ }^{\mathrm{b}, 2}$ \\ ${ }^{a}$ Advanced Materials and Engineering, Manufacturing Cluster, Council for Scientific and Industrial Research, Meiring Naudé Road, \\ Brummeria, Pretoria 0185, South Africa \\ ' SChool of Chemical and Metallurgical Engineering and DSI-NRF Centre of Excellence in Strong Materials, University of the Witwatersrand, \\ Johannesburg, South Africa \\ Email:mseerane@csir.co.za*,rmahlangu1@csir.co.za', Lesley.Cornish@wits.ac.za²
}

\begin{abstract}
High alloyed $\beta$-phase stabilised titanium alloys are known to have low elastic moduli comparable to that of the human bone $(\approx 30 \mathrm{GPa})$. The $\beta$-phase in titanium alloys exhibits an elastic modulus of about 60-80 GPa, which is nearly half that of $\alpha$-phase (100-120 GPa). In this work, an attempt to develop a $\beta$-phase titanium-based alloy through first-principles calculations and Thermo-Calc calculations for biomedical applications was conducted. First-principles calculations were performed using the CASTEP code on a simple 2-atom bcc unit cell to predict the theoretical elastic modulus and mechanical stability of the Ti-Nb-Ta-Zr (TNTZ) system at $0 \mathrm{~K}$. Thermo-Calc was used to determine the phase proportion diagrams of the proposed alloys at $500^{\circ} \mathrm{C}$. The alloy comprised $\mathrm{Ti}_{-}-\mathrm{Nb}_{x}-\mathrm{Ta}_{25}-\mathrm{Zr}_{5}(x=5,10$, $20,30,40)\left(\right.$ at.\%). The theoretical results suggested that increasing niobium content introduced both mechanical $\left(c^{\prime}>0\right)$ stability of the alloys. Alloy Ti- $-\mathrm{Nb}_{5}-\mathrm{Ta}_{25}-\mathrm{Zr}_{5}$ gave the lowest elastic modulus of $55.23 \pm 24.45 \mathrm{GPa}$ which is half the elastic modulus of pure titanium $(\alpha$ phase). The phase proportion diagrams showed that up to $58.6 \mathrm{~mol} \%$ of $\beta$ phase was retained at 20 at.\% Nb, although the Voigt-ReussHill Young's modulus calculated from first principles increased with increasing niobium content while the $\alpha / \beta$ phase transformation temperature decreased down to $551.3^{\circ} \mathrm{C}$ at 40 at. $\% \mathrm{Nb}$.
\end{abstract}

Keywords: Titanium alloys, Elastic modulus, First principles, Thermo-Calc

\section{Introduction}

Metallic implants such as stainless steel, cobalt-chromium based alloys and titanium and its alloys are preferred biomaterials, especially in areas requiring superior mechanical strength (Mohammed, Khan, \& Siddiquee, 2014). Amongst the currently used metallic biomaterials, titanium-based alloys are extensively used due to their excellent biocompatibility, corrosion resistance, wear resistance, high specific strength, as well as low modulus of elasticity relative to other conventional metallic biomaterials (Kuroda \& et al., 1998; Niinomi, 2008). Amongst all these excellent properties of titanium alloys, the modulus of elasticity is one of the key drivers for developing these alloys for biomedical applications. High elastic modulus puts serious limitations on the performance of titanium alloys as implants, especially for artificial joints e.g. knee, shoulder, hip. An implant with higher stiffness relative to that of the adjacent bone results in bone resorption (Niinomi, Liu, Nakai, Liu, \& Li, 2016) and cell death around the implant and consequently osteoporosis or implant loosening (Gaaser, 2001). This biomechanical incompatibility is called the "stress shielding effect" (Sumnar, Turner, Igloria, Urban, \& Galante, 1998). It is therefore essential that the elastic modulus or stiffness of the implant is as close to that of the connected bone as possible, to facilitate effective transfer of mechanical stress needed by the bone (Sumner \& Galante, 1992; Mohammed, Khan, \& Siddiquee, 2014).
Commercially pure (CP) titanium and the Ti-6Al-4V alloy (ASTM F1108) are currently the most commonly used materials as structural biomaterials for orthopaedic prosthesis and dental implants (Niinomi, Fatigue performance and cyto-toxicity of low rigidity titanium alloy, Ti-29Nb-13Ta-4.6Zr, 2003; Geetha \& et al., 2009) (Geetha \& et al., 2009; Niinomi, 2003). However, Al and $\mathrm{V}$ in Ti-6Al-4V are associated with long-term health problems such Alzheimer's, neuropathy and ostemomalacia (Nag, Banerjee, \& Fraser, 2005). Vanadium is toxic, both in elemental and oxide $\left(\mathrm{V}_{2} \mathrm{O}_{5}\right)$ form, and it alters the kinetic activity of enzymes in the body tissues. This phenomenon is associated with inflammatory response of the cells (Okazaki, Ito, Kyo, \& Tateishi, 1996). The release of aluminium ions into the tissues potentially causes Alzheimer's disease (Ikeda, Komatsu, Sowa, \& Niinomi, 2002). As well as the toxicity of the alloying elements, the biomechanical incompatibility (i.e. high elastic or Young's modulus) of commercially (CP) titanium ( 100 GPa) and Ti-6Al-4V ( 110-112 GPa) (Long \& Rack, 1998) implants relative to that of the human bone (10-30 GPa) (Miura, Yamada, Hanada, Jung, \& Itoi, 2011) is problematic. The $\alpha \mathrm{Ti}$ phase in $\mathrm{CP}$ titanium and Ti-6Al-4V alloy promotes the high elastic modulus of the materials (Gross \& Abel, 2001; Geetha \& et al., 2009).

Recent trends in research and development of biomedical titanium alloys include low elastic modulus titanium-based alloys, also referred to as second generation biomaterials or beta $(\beta)$ type titanium alloys, Table 1 . These alloys must contain non-toxic and 
Table 1: Titanium-based alloys and their respective mechanical properties for biomedical applications (Geetha \& et al., 2009)

\begin{tabular}{ccccc}
\hline Material & Standard & Modulus (GPa) & Tensile strength (MPa) & Alloy type \\
\hline & $\mathbf{1}^{\text {st }}$ generation biomaterials (1950-1990) & & \\
\hline CP Ti (grade 1-4) & ASTM 1341 & 100 & $240-550$ & $\alpha$ \\
Ti-6Al-4V ELI & ASTM F136, F1472 & $110-112$ & $860-930$ & $\alpha+\beta$ \\
Ti-6Al-7Nb & ASTM F1295 & 110 & $900-1050$ & $\alpha+\beta$ \\
Ti-5Al-2.5Fe & - & 110 & 1020 & $\alpha+\beta$ \\
& 2 $^{\text {nd }}$ generation biomaterials (1990-to date) & & Metastable $\beta$ \\
Ti-13Nb-13Zr & ASTM F1713 & $79-84$ & $973-1037$ & $\beta$ \\
Ti-12Mo-6Zr-2Fe & ASTM F1813 & $74-85$ & $1060-1100$ & $\beta$ \\
Ti-35Nb-7Zr-5Ta & - & 55 & 596 & $\beta$ \\
Ti-29Nb-13Ta-4.6Zr & - & 65 & 911 & 1010 \\
Ti-35Nb-5Ta-7Zr-0.4O & - & 66 & - & $\beta$ \\
Ti-15Mo-5Zr-3Al & - & 82 & - & $\beta$ \\
Ti-Mo & ASTM F2066 & - & \\
\hline
\end{tabular}

non-allergic elements and must possess excellent biomechanical properties (Li, Hao, Yang, Cui, \& Niinomi, 2002; Li, et al., 2014; Wang, et al., 2016). Generally, elastic modulus decreases with increased volume fraction of the $\beta$ phase. The elements that are known to enhance the volume fraction of $\beta$ phase in titanium alloys by stabilising the $\beta$ phase are $\mathrm{Nb}, \mathrm{Ta}, \mathrm{Mo}, \mathrm{Zr}, \mathrm{Cr}$ and $\mathrm{V}$ (Niinomi, 2002; Ikehata, et al., 2004; Abdel-Hady, Hinoshitaa, \& Morinagaa, 2006; Karre, Niranjan, \& Dey, 2015).

Niobium and tantalum are typically considered the most potent $\beta$ stabilisers and effectively reduce the elastic modulus (Yang, et al., 2018). Zirconium is considered a neutral element and weak $\beta$ stabiliser in the Ti-Zr alloy system (Correa, et al., 2015). However, in the Ti-Zr-Nb system, zirconium acts as a potent $\beta$ stabiliser (Brailovsky, et al., 2011). Kim et al. (2020) studied Ti-Nb-Zr (Nb $=12-40, \mathrm{Zr}=0-18)($ at.\%), finding that the minimum $\mathrm{Nb}$ content to maintain the $\beta$ phase at room temperature continuously decreased with increasing $\mathrm{Zr}$ content. Wang et al. (Wang, et al., 2018) studied the Ti-Zr alloy in the composition range of 5 to $45 \mathrm{wt} \% \mathrm{Zr}$ and that only $\alpha$ and $\alpha^{\prime}$ phases existed in the entire composition range. Niobium and tantalum are more expensive and denser than pure titanium, so addition of large amounts of these metals is not economically viable and would also lead to considerable increase in the density of the $\beta$-type titanium alloys (Yang, et al., 2018). Thus, this work focused on developing compatible Ti-Nb-Ta-Zr alloys for biomedical applications by computational calculations, i.e. first principles calculations and Thermo-Calc calculations. The computational approach would reduce experimental effort, because they would identify good starting compositions, and hence reduce experimental time and consumption of the expensive metal powders $(\mathrm{Nb}$, Ta and $\mathrm{Zr})$. The alloys compositions comprised Ti$\mathrm{Nb}_{x}-\mathrm{Ta}_{25}-\mathrm{Zr}_{5}(x=5,10,20,30,40)$ (at.\%).

\section{Computational methodology}

\subsection{First principles calculations}

First principles calculations for the proposed $\beta$-type alloy Ti$\mathrm{Nb}_{x}-\mathrm{Ta}_{25}-\mathrm{Zr}_{5}(x=5,10,20,30,40)($ at.\%) were conducted using density functional theory (DFT) within the generalised gradient
approximation(GGA) (Burke, Perdew, \& Wang, 1998) implemented in the Cambridge Serial Total-Energy Package (CASTEP) code (Clark, et al., 2005). The cut-off energy convergence used was $669.4 \mathrm{eV}$ for the plane-wave basis, and the structural relaxation the Brillouin Zone (BZ) was sampled with a Monkhorst-Pack k-point grid (Monkhorst \& Pack, 1976) of $\left(18 / \mathrm{n}_{1}\right) \times\left(18 / \mathrm{n}_{2}\right) \times\left(18 / \mathrm{n}_{3}\right)$ for the $\mathrm{n}_{1} \times \mathrm{n}_{2} \times \mathrm{n}_{3}$ bcc $\beta$ Ti unit cell (where $\mathrm{n}_{1}, \mathrm{n}_{2}$ and $\mathrm{n}_{3}$ are the numbers of the unit cells taken in the $\mathrm{x}, \mathrm{y}$ and $\mathrm{z}$-directions, and equated to 1 for all the calculations). The lattice constants were optimised using the Broyden-Fletcher-Goldfarb-Shanno (BFGS) (Fischer \& Almlof, 1992) minimisation algorithm at zero pressure from first-principles. The calculations were done at $0 \mathrm{~K}$ and the atoms were kept fixed at their lattice positions. The polycrystalline elastic properties were estimated as a function of composition based on the Voigt-Reuss-Hill approach. Voigt gives the upper elastic bound due to the assumption of constant strain in all grains, Reuss gives the lower bound due to the assumption of constant stress in all grains, and the Hill approach is the average of Voigt and Reuss which gives the closest figure to the polycrystalline value (Chung $\&$ Buessem, 1967). All the calculations were run at a maximum number of iterations of 100 .

\subsection{Thermo-Calc}

The thermodynamic equilibrium of a system at constant pressure is given by the minimum of the Gibbs free energy, $\Delta G_{f}^{o}$. For multiphase equilibria, the sum of the molar Gibbs energies for the stable phases is at minimum when $\Delta G_{f}^{o}=\sum_{\varnothing} n^{\varnothing} G_{m}^{\varnothing}$ (Kattner, 2016), where $n^{\varnothing}$ is the number of moles and $G_{m}^{\emptyset}$ is the molar Gibbs energy of phase $\varnothing$. Thermo-Calc is used to evaluate Gibbs energy parameters as a function of individual phases (Sundman, Jansson, \& Andersson, 1985; Prins, Cornish, Stumpf, \& Sundman, 2003; Liu, 2009). The database of the parameterised Gibbs energy function is usually built from the pure elements, and phases in binary and ternary alloys, and can be used to extrapolate thermodynamic properties of phases in alloys as a function of composition, temperature or pressure. In this work, the Gibbs energy functions of pure Ti, $\mathrm{Nb}$, Ta and $\mathrm{Zr}$ for the Ti-Nb $-\mathrm{Ta}_{25}-\mathrm{Zr}_{5}(x=5,10,20,30,40)$ (at.\%) alloys were taken from the SSOL4 database in the Thermo- 
Calc 2020a version. Single point equilibrium (SPE) calculations were performed to show stable phases and their compositions at $500^{\circ} \mathrm{C}$ and a pressure of $100 \mathrm{kPa}$. Calculations were also performed between $100^{\circ} \mathrm{C}$ and $2000^{\circ} \mathrm{C}$ to plot the proportions of phases as a function temperature.

\section{Results and discussion}

\subsection{First principles calculations}

Table 2 shows elasticity results of various alloys. For mechanically stable crystals, the independent elastic constants should satisfy the well-known Born stability criteria (Born, 1940), which for cubic structures is $c_{11}>0, c_{44}>0, c_{11}>\left|c_{12}\right|$ and $c_{11}+2 c_{12}>0$.

In Table 2, the estimated elastic constants satisfied the Born stability criteria (Born, 1940). In addition, the increasing shear modulus, $c^{\prime}$, indicated that the alloys became more stable as the niobium concentration increased, Figure 1. The Cauchy pressure, $c^{\prime \prime}$, is used to ascertain the kind of bonds for metals and compounds (Pettifor, 1992). Brik (2010) observed that $c^{\prime \prime}$ is positive for most ionic bonds (e.g. metallic) and negative for most covalent bonds (non-metallic). Increasing values of Cauchy pressure relative to the $\mathrm{Nb}$ content confirmed that the metallic behavior of $\mathrm{Ti}^{-} \mathrm{Nb}_{x}$ $\mathrm{Ta}_{25}-\mathrm{Zr}_{5}$ alloys became stronger with increasing $\mathrm{Nb}$. The Zener anisotropy factor, $A$, is an indication of the degree of anisotropy in solids (Zener, 1948). For $A=1$, the material is completely isotropic, whereas deviations from unity indicate the degree of elastic anisotropy which is defined as (Chung \& Buessem, 1967): $A^{*}=\left[3(A-1)^{2}\right] /\left[3(A-1)^{2}+25 A\right]$

Elastic anisotropy is the directional dependence of mechanical properties of a material, such as formation of micro-cracks, movement of cracks, development of plastic deformation (Naher $\&$ Naqib, 2021). $A^{*}$ has the following properties of practical importance:

(a) $A *$ is zero for the crystals of elastic isotropy, i.e. for $A=1$, (b) for an anisotropic crystal $A^{*}$ is a single-valued measure of the elastic anisotropy regardless of whether $A<1$ or $A>1$ and (c) $A^{*}$ gives a relative magnitude of the actual elastic anisotropy possessed by a crystal (Chung \& Buessem, 1967).

The bec crystal structure of alloys $\mathrm{Ti}-\mathrm{Nb}_{5}-\mathrm{Ta}_{25}-\mathrm{Zr}_{5}, \mathrm{Ti}_{-}-\mathrm{Nb}_{10}-\mathrm{Ta}_{25}-$ $\mathrm{Zr}_{5}$ and $\mathrm{Ti}-\mathrm{Nb}_{20}-\mathrm{Ta}_{25}-\mathrm{Zr}_{5}$ was more elastically anisotropic than alloys Ti- $\mathrm{Nb}_{30}-\mathrm{Ta}_{25}-\mathrm{Zr}_{5}$ and $\mathrm{Ti}-\mathrm{Nb}_{40}-\mathrm{Ta}_{25}-\mathrm{Zr}_{5}$.

Figure 1 also shows the lattice parameter $(a)$ and shear modulus $\left(c^{\prime}\right)$ of the bcc phase as a function of $\mathrm{Nb}$ content. The lattice parameter increased with increasing $\mathrm{Nb}$ concentration, which is

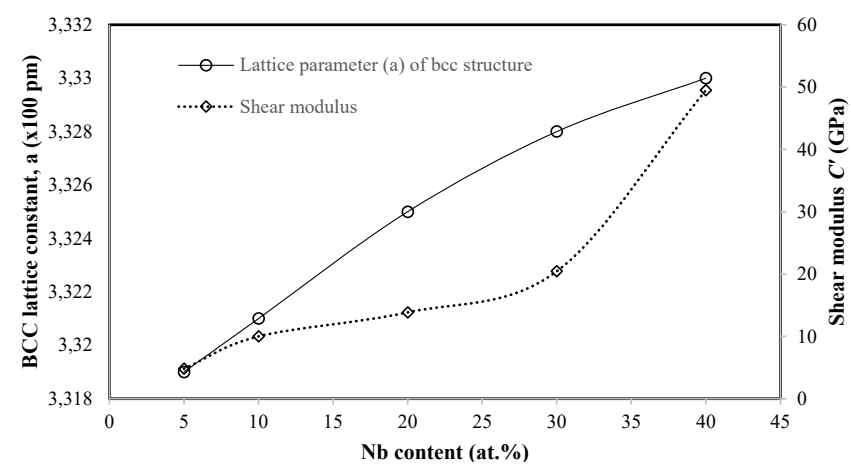

Figure 1: Effect of niobium content on lattice parameter and shear modulus $\mathrm{Ti}-\mathrm{Nb}_{\mathrm{x}}-\mathrm{Ta}_{25}-\mathrm{Zr}_{5}$ alloys at $0 \mathrm{~K}$

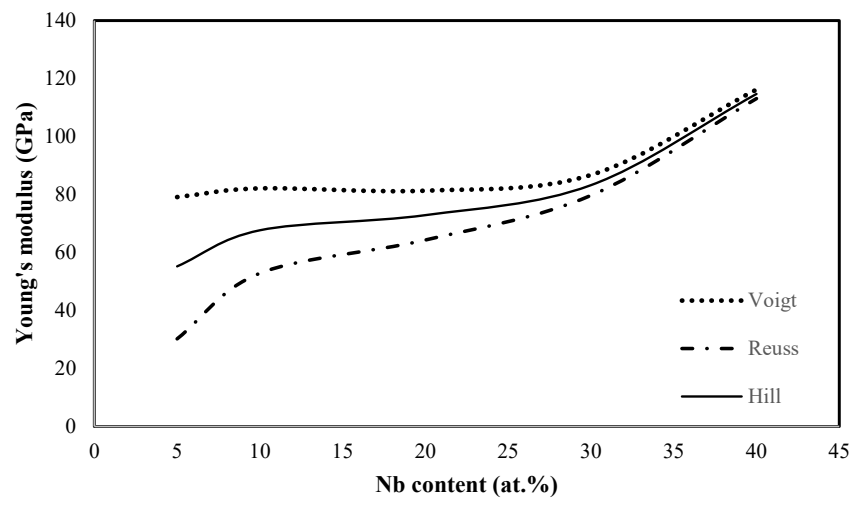

Figure 2: Effect of niobium content on Young's modulus of $\mathrm{Ti}-\mathrm{Nb}_{\mathrm{x}}-\mathrm{Ta}_{25}-\mathrm{Zr}_{5}(\mathrm{x}=5,10,20,30,40($ at.\%) at $0 \mathrm{~K}$

due to the relative atomic sizes of $\mathrm{Ti}(176 \mathrm{pm})$ and $\mathrm{Nb}(198 \mathrm{pm})$ (WolframResearch, 2021). The atomic size of niobium is larger than that of titanium, hence an increase in the lattice parameter as $\mathrm{Nb}$ content increased

Figure 2 shows the change in Young's modulus with $\mathrm{Nb}$ content, using the Voigt-Reuss-Hill (VRH) approximation. Young's modulus is defined as the ratio of uniaxial stress and axial strain, and is a measurement of the stiffness (Pugh, 1954) (larger Young's moduli indicate stiffer materials). The VRH approximation can provide satisfactory estimations of elastic moduli. The lowest averaged Young's modulus (Hill) obtained was $55.23 \pm 24.5 \mathrm{GPa}$ for the $\mathrm{Ti}-\mathrm{Nb}_{5}-\mathrm{Ta}_{25}-\mathrm{Zr}_{5}$ alloy, although this had large scatter.

\subsection{Thermo-Calc calculations}

Figure 3 shows the phase proportion diagrams of the alloys as a function of temperature. Increased $\mathrm{Nb}$ content gradually reduced the start of $\beta \rightarrow \alpha$ transformation temperature from $882^{\circ} \mathrm{C}$ for $\mathrm{CP}$ titanium to $551.3^{\circ} \mathrm{C}$ for 40 at. $\% \mathrm{Nb}$. Alloys Ti- $-\mathrm{Nb}_{30}-\mathrm{Ta}_{25}-\mathrm{Zr}_{5}$ and Ti-

Table 2: Elastic properties of $\mathrm{Ti}-\mathrm{Nb}_{\mathrm{x}}-\mathrm{Ta}_{25}-\mathrm{Zr}_{5}$ alloys at $0 \mathrm{~K}$

\begin{tabular}{cccccccc}
\hline Nb (at.\%) & $\boldsymbol{c}_{11}$ & $\boldsymbol{c}_{\boldsymbol{1 4}}$ & $\boldsymbol{c}_{\boldsymbol{1 2}}$ & $\boldsymbol{c}^{\prime}$ & $\boldsymbol{c}^{\prime \prime}$ & $\boldsymbol{A}^{\prime}$ & $\boldsymbol{A}^{*}$ \\
\hline 5 & 133.4 & 44.02 & 123.8 & 4.80 & 79.78 & 9.171 & 0.466 \\
10 & 143.8 & 42.40 & 123.8 & 10.0 & 81.40 & 4.24 & 0.229 \\
20 & 155.3 & 39.14 & 127.6 & 13.85 & 88.46 & 2.826 & 0.124 \\
30 & 170.5 & 38.02 & 129.6 & 20.45 & 91.58 & 1.859 & 0.0455 \\
40 & 311.7 & 35.13 & 212.7 & 49.5 & 177.6 & 0.7097 & 0.0140 \\
\hline
\end{tabular}

${ }^{*} c^{\prime}=1 / 2\left(c_{11}-c_{12}\right), c^{\prime \prime}=c_{12}-c_{44} A=2 c_{44} /\left(c_{11}-c_{12}\right)$ 


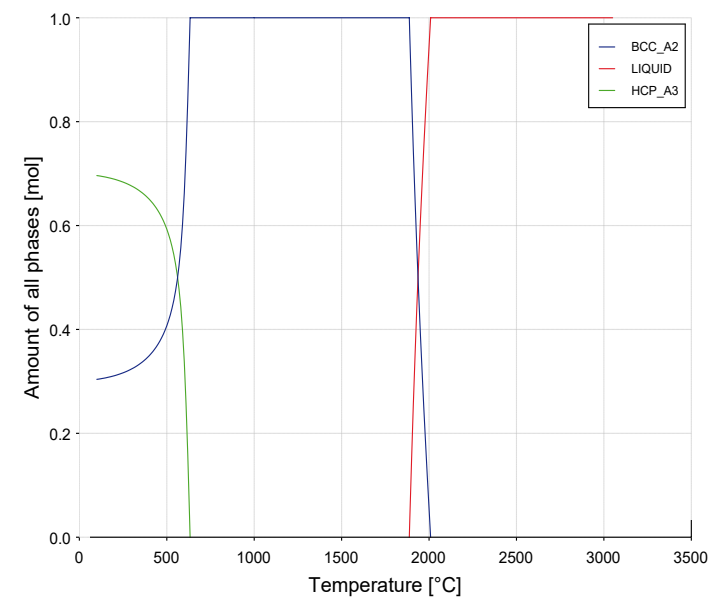

$\mathrm{Ti}-\mathrm{Nb}_{5}-\mathrm{Ta}_{25}-\mathrm{Zr}_{5}$

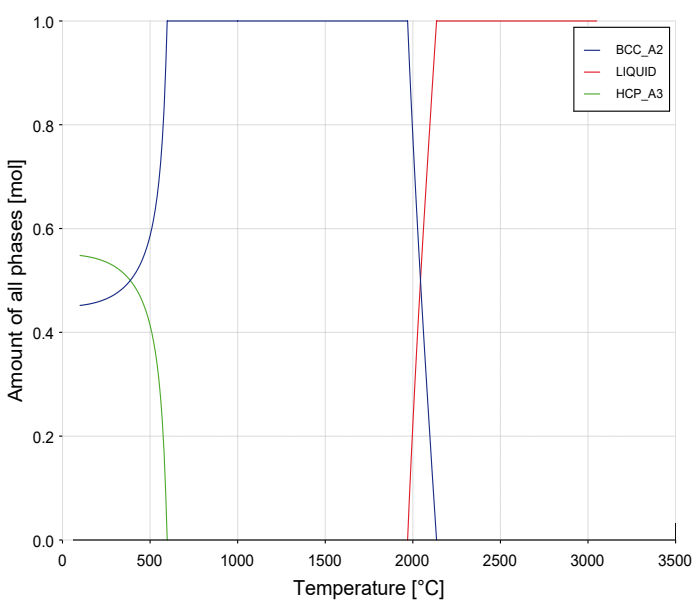

$\mathrm{Ti}-\mathrm{Nb}_{20}-\mathrm{Ta}_{25}-\mathrm{Zr}_{5}$

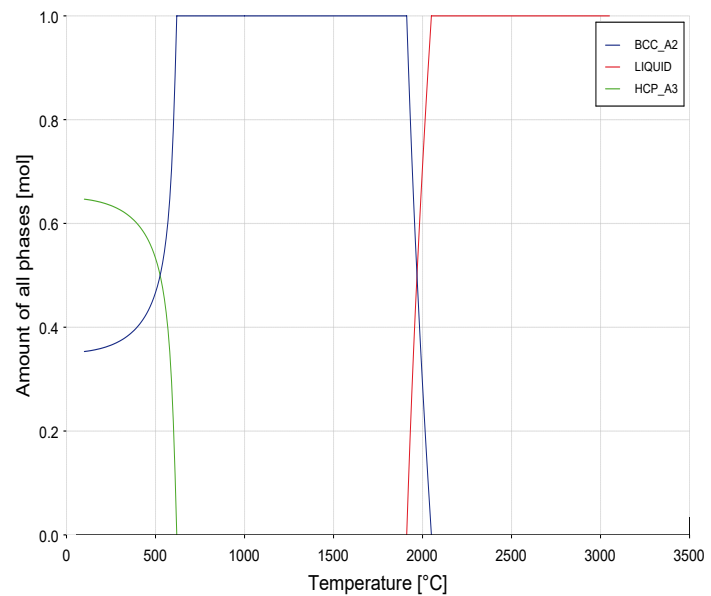

$\mathrm{Ti}-\mathrm{Nb}_{10}-\mathrm{Ta}_{25}-\mathrm{Zr}_{5}$

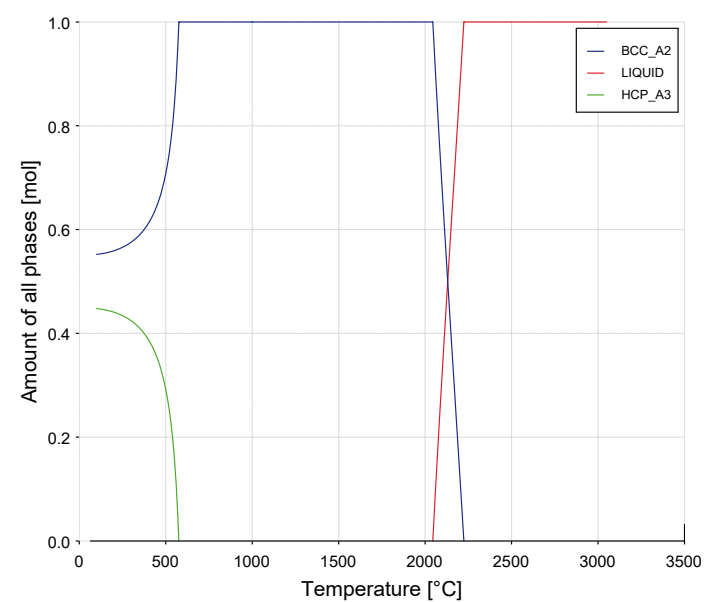

$\mathrm{Ti}-\mathrm{Nb}_{30}-\mathrm{Ta}_{25}-\mathrm{Zr}_{5}$

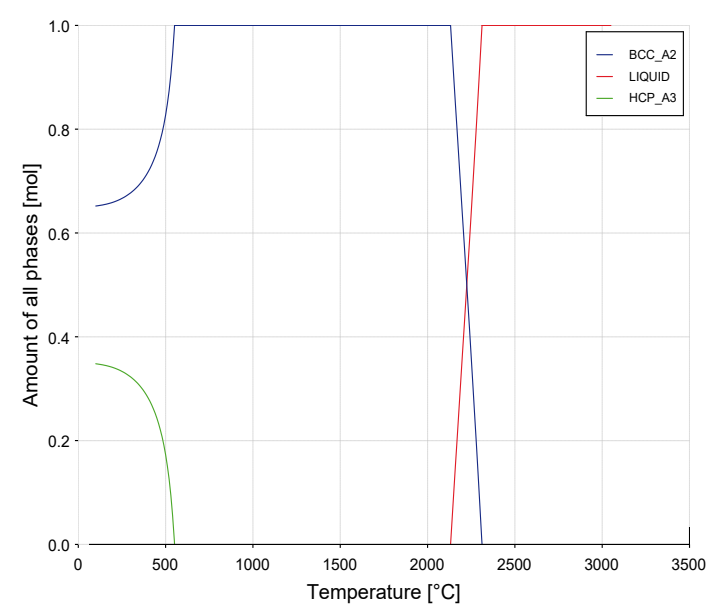

$\mathrm{Ti}-\mathrm{Nb}_{40}-\mathrm{Ta}_{25}-\mathrm{Zr}_{5}$

Figure 3: Calculated phase proportion diagrams of $\mathrm{Ti}^{-}-\mathrm{Nb}_{\mathrm{x}}-\mathrm{Ta}_{25}-\mathrm{Zr}_{5}(\mathrm{x}=5,10,20,30,40$ at.\%) 


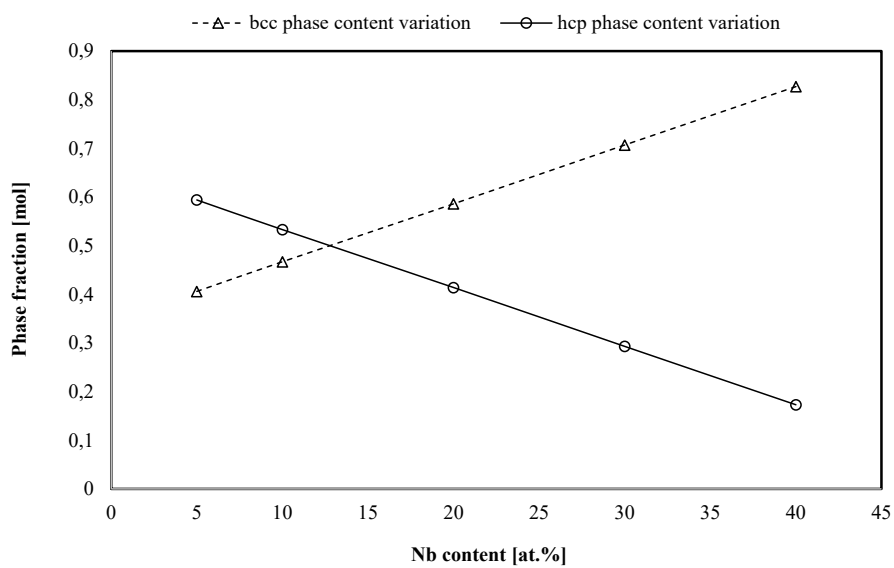

Figure 4: Phase proportions of $\alpha$ (hcp) and $\beta$ (bcc) as a function of niobium content at $500^{\circ} \mathrm{C}$

$\mathrm{Nb}_{40}-\mathrm{Ta}_{25}-\mathrm{Zr}_{5}$ were favourable, since more $\beta$ phase was stabilised compared to other alloys. This can be attributed to the higher $\mathrm{Nb}$ content as a stronger $\beta$ stabiliser (Yang, et al., 2018).

Figure 4 shows the variation in phase proportion with $\mathrm{Nb}$ content. The data were generated from single point equilibrium (SPE) calculations and only two equilibrium phases $(\alpha$ and $\beta$ ) were observed. The amount of $\beta$ (bcc) phase increased with increasing $\mathrm{Nb}$ content, thus confirming the potency of $\mathrm{Nb}$ as a $\beta$ stabiliser. At 20 at.\% $\mathrm{Nb}$, the amount of equilibrium $\beta$ phase was $58.6 \mathrm{~mol} \%$ at $500^{\circ} \mathrm{C}$, i.e. more than the $\alpha$ phase. The experimental results of Okazi et al. (2004), Kim et al. (2006) and Gutierrize et al. (2014) showed that the $\beta$ phase was the major phase in alloys with higher than 25 at. $\% \mathrm{Nb}$.

The increasing $\beta$ content with increasing $\mathrm{Nb}$ content (Figures 3 and 4) is, however, not in agreement with the predicted elastic Young's modulus from first principles calculations (Figure 2). As noted by Niinomi (2008), increasing $\beta$ phase content contributes significantly to the reduction of the elastic Young's modulus. However, the first principles results (Figure 2) agreed well with Wang et al. (2016).

In summary, first principles calculations showed $\mathrm{Ti}-\mathrm{Nb}_{5}-\mathrm{Ta}_{25}-\mathrm{Zr}_{5}$ as the potential alloy due to its lower elastic Young's modulus with a positive shear modulus. In addition, the calculations from ThermoCalc showed that over 50 mol.\% of $\beta$ phase can be achieved at a minimum $\mathrm{Nb}$ content of 20 at.\% The phase stability analysis for the alloys will be done in future studies through the application of Pandat software package.

\section{Conclusions}

a. First principles density functional theory (DFT) within generalized gradient approximation (GGA) was conducted at 0 $\mathrm{K}$ to determine the elastic properties (Young's modulus, shear modulus, Cauchy pressure, elastic anisotropy and the bec lattice constant) of alloys $\mathrm{Ti}-\mathrm{Nb}_{x}-\mathrm{Ta}_{25}-\mathrm{Zr}_{5}(x=5,10,20,30,40)$ at. $\%$ in a CASTEP code.

b. Increased $\mathrm{Nb}$ content to 40 at.\% improved the mechanical stability and isotropy of the alloys. c. Increased $\mathrm{Nb}$ content to 40 at.\% increased the lattice parameter while the alloys remained mechanically stable, shown by the calculated shear moduli $\left(c^{\prime}>0\right)$.

d. The Voigt-Reuss-Hill approximation showed that the Young's modulus increased with $\mathrm{Nb}$ content to 40 at.\%. Alloy Ti-Nb ${ }_{5}$ $\mathrm{Ta}_{25}-\mathrm{Zr}_{5}$ had the lowest Young's modulus of $55.3 \pm 24.45 \mathrm{GPa}$ (although this had large scatter) and this value is closest to the cortical Young's modulus of the human bone.

e. Thermo-Calc calculations were used to investigate the equilibrium phase proportions of the proposed alloys using SSOL4 database.

f. Thermo-Calc showed that the $\beta$ phase became more stable with increased $\mathrm{Nb}$ content.

g. Up to $58.6 \mathrm{~mol} \%$ of $\beta$ phase was achieved at 20 at. $\% \mathrm{Nb}$ at $500^{\circ} \mathrm{C}$. The transformation temperatures decreased as the $\mathrm{Nb}$ content was increased, with alloy $\mathrm{Ti}-\mathrm{Nb}_{40}-\mathrm{Ta}_{25}-\mathrm{Zr}_{5}$ reaching the lowest phase transformation temperature of $551.3^{\circ} \mathrm{C}$.

\section{Acknowledgements}

The authors would like to acknowledge CSIR (Advanced Materials Engineering - AME and Centre for High Performance Computing - CHPC) for providing Materials Studio software package to run first principles calculations and Mintek for making Thermo-Calc software available to run thermodynamic calculations. The authors would also like to extend their gratitude to David Tshwane for guiding first principles calculation methods, and Nomsombuluko Masia and Marandela Mulaudzi for providing their inputs in Thermo-Calc calculations method.

\section{Contribution of each author}

M N Madigoe: Conceptualisation, Design of the work, Data acquisition, analysis and interpretation, writing and editing of the manuscript. R Modiba: First principles calculations and interpretation, Critical revising and editing of the manuscript. L A Cornish: Data interpretation (first principles and Thermo-Calc calculations), Critical reviewing and editing of the manuscript, Final approval of the manuscript.

\section{References}

1. Abdel-Hady, M., Hinoshitaa, K., \& Morinagaa, M. (2006). General approach to phase stability and elastic properties of $\beta$-type Ti alloys using electronic parameters. Scripta Materialia, 55, 477-480.

2. Born, M. (1940). On the stability of crystal lattices I. Mathematical Proceedings of the Cambridge Philosophical Society, 36(2), 160-172.

3. Brailovsky, V., Prokoshkin, S., Gauthier, M., Inaekyan, K., Dubinskiy, S., Petrzhik, M., \& Filonov, M. (2011). Bulk and porous metastable beta $\mathrm{Ti}-\mathrm{Nb}-\mathrm{Zr}(\mathrm{Ta})$ alloys for biomedical applications. Materials Science and Engineering C, 31, 643-657.

4. Brik, M. G. (2010). First-principles calculations of electronic, optical and elastic properties of ZnA12S4 and ZnGa2O4. Journal of Physics and Chemistry of Solids, 71, 1435-1442.

5. Burke, K., Perdew, J. P., \& Wang, Y. (1998). Derivation of a Generalized Gradient Approximation: The PW91 Density Functional. In J. F. Dobson, G. Vignale, \& M. P. Das (Eds.), Electronic Density Functional Theory. Boston: Springer.

6. Chung, D. H., \& Buessem, W. R. (1967). The Voigt-Reuss-Hill approximation and elastic moduli of polycrystalline $\mathrm{MgO}, \mathrm{CaF} 2$, beta-ZnS, ZnSe, and CdTe. Journal of Applied Physics, 38, 2535-2540.

7. Clark, S. J., Segall, M. D., Pickard, C. J., Hasnip, P. J., Probert, M J., Refson, K., \& Payne, M. C. (2005). First principles methods using CASTEP. Zeitschrift fuer Kristallographie, 220(5-6), 567-570.

8. Correa, D. R., Vicente, F. B., Araujo, R. O., Lourenco, M. L., Kuroda, P. A., Buzalaf, M. A., \& Grandini, C. R. (2015). Effect of the substitutional elements on the microstructure of the Ti-15Mo-Zr 
and Ti-15Zr-Mo systems alloys. Journal of Materials Research and Technology, 4(2), 180-185.

9. Fischer, T. H., \& Almlof, J. (1992). General methods for geometry and wave function optimization. The Journal of Physical Chemistry, 96, 9768-9774.

10. Gaaser, B. (2001). Design and Engineering Criteria for Titanium Devices - Titanium in Medicine. Berlin: Springer.

11. Geetha, M., \& et al. (2009). Ti based biomaterials, the ultimate choice for orthopaedic implants - A review. Progress in Materials Science, 54, 397-425.

12. Gross, S., \& Abel, E. W. (2001). A finite element analysis of hollow stemmed hip prostheses as a means of reducing stress shielding of the femur. Journal of Biomechanics, 34, 995-1003.

13. Gutierrize-Moreno, J. J., Guo, Y., Georgarakis, K., Yavari, A. R., Evangelakis, G. A., \& Lekka, C. E. (2014). The role of Sn doping in the $\beta$-type Ti-25 at $\% \mathrm{Nb}$ alloys: Experiment and ab initio calculations. Journal of Alloys and Compounds, 615, 676-679.

14. Ikeda, M., Komatsu, S.-Y., Sowa, I., \& Niinomi, M. (2002). Aging Behavior of the Ti-29Nb-13Ta-4.6Zr New Beta Alloy for Medical Implants. Metallurgical and Materials Transactions A, 33, 487-493.

15. Ikehata, I., Nagasako, N., Furuta, T., Fukumoto, A., Miwa, K., \& Saito, T. (2004). First-principles calculations for development of low elastic modulus Ti alloys. Physical Review B, 70, 174113-174118.

16. Karre, P., Niranjan, M. K., \& Dey, S. R. (2015). First principles theoretical investigation of low Young's modulus beta $\mathrm{Ti}-\mathrm{Nb}$ and $\mathrm{Ti}-\mathrm{Nb}-\mathrm{Zr}$ alloys compositions for biomedical applications. Materials Science and Engineering C, 50, 52-58.

17. Kattner, U. R. (2016). The calphad method and its role in material and process development. Tecnologia em Metalurgia, Materiais e Mineracao, 13(1), 3-15.

18. Kim, H. Y., \& et al. (2006). Martensitic transformation, shape memory effect and superelasticity of Ti-Nb binary alloys. Acta Materialia, 54, 2419-2429.

19. Kim, K. M., Kim, H. Y., \& Miyazaki, S. (2020). Effect of Zr content on phase stability, deformation behavior, and Young's modulus in Ti-Nb-Zr alloys. Materials, 13, 1-14.

20. Kuroda, D., \& et al. (1998). Design and mechanical properties of new beta type titanium alloys for implant materials. Materials Science and Engineering A, 243(1-2), 244-249.

21. Li, S., Hao, Y., Yang, R., Cui, Y., \& Niinomi, M. (2002). Effect of $\mathrm{Nb}$ on Microstructural Characteristics of $\mathrm{Ti}-\mathrm{Nb}-\mathrm{Ta}-\mathrm{Zr}$ Alloy for Biomedical Applications. Materials Transactions, 43(12), 2964-2969.

22. Li, Y., Yang, C., Zhao, H., Qu, S., Li, X., \& Li, Y. (2014). New Developments of Ti-Based Alloys for Biomedical Applications. Materials, 7, 1709-1800. doi:10.3390/ma7031709

23. Liu, Z.-K. (2009). First-principles calculations and CALPHAD modeling of thermodynamics. Journal of Phase Equilibria and Diffusion, 30, 517-534.

24. Long, M., \& Rack, H. J. (1998). Titanium alloys in total joint replacement - a materials science perspective. Biomaterials, 19, 1621-1639.

25. Miura, K., Yamada, N., Hanada, S., Jung, T.-K., \& Itoi, E. (2011). The bone tissue compatibility of a new Ti-Nb-Sn alloy with a low Young's modulus. Acta Biomaterialia, 7, 2320-2326. doi:10.1016/j. actbio.2011.02.008

26. Mohammed, M. T., Khan, Z. A., \& Siddiquee, A. N. (2014). Beta Titanium Alloys: The Lowest Elastic Modulus for Biomedical Applications: A Review. International Journal of Materials and Metallurgical Engineering, 8(8), 822-827.

27. Monkhorst, H. J., \& Pack, J. D. (1976). Special points for Brillouinzone integrations. Physical Review B, 13, 5188-5192.
28. Nag, S., Banerjee, R., \& Fraser, H. L. (2005). Microstructural evolution and strengthening mechanisms in Ti-Nb-Zr-Ta, Ti-Mo-Zr-Fe and Ti-15Mo biocompatible alloys. Materials Science and Engineering C, 25(3), 357-362. doi:10.1016/j.msec.2004.12.013

29. Niinomi, M. (2002). Recent metallic materials for biomedica applications. Metallurgical and Materials Transaction A, 33, 477-486.

30. Niinomi, M. (2003). Fatigue performance and cyto-toxicity of low rigidity titanium alloy, Ti-29Nb-13Ta-4.6Zr. Biomaterials, 24 , 2673-2683.

31. Niinomi, M. (2008). Mechanical biocompatibilities of titanium alloys for biomedical applications. Journal of the Mechanical Behavior of Biomedical Materials, 1, 30-42.

32. Niinomi, M., Liu, Y., Nakai, M., Liu, H., \& Li, H. (2016). Biomedical titanium alloys with Young's moduli close to that of cortical bone. Regenerative Biomaterials, 173-185.

33. Okazaki, Y., Ito, Y., Kyo, K., \& Tateishi, T. (1996). Corrosion resistance and corrosion fatigue strength of new titanium alloys for medical implants without $\mathrm{V}$ and $\mathrm{Al}$. Materials Science and Engineering A, 213, 138-147.

34. Oshida, Y. (2007). Bioscience and Bioengineering of Titanium Materials (1st ed.). Oxford: Elsevier Science.

35. Ozaki, T., \& et al. (2004). Beta Ti alloys with low Young's modulus. Materials Transaction, 45(8), 2776-2779.

36. Pettifor, D. G. (1992). Theoretical predictions of structure and related properties of intermetallics. Materials Science and Technology, 8(4), 345-349.

37. Prakasam, M., Locs, J., Salma-Ancane, K., Loca, D., Largeteau, A., \& Berzina-Cimdina, L. (2017). Biodegradable Materials and Metallic Implants - A Review. Journal of Functional Biomaterials, 8(44), 1-15. doi:10.3390/jfb8040044

38. Prins, S. N., Cornish, L. A., Stumpf, W. E., \& Sundman, B. (2003). Thermodynamic assessment of the Al-Ru system. Calphad, 27(1), 79-90.

39. Pugh, S. F. (1954). XCII. Relations between the elastic moduli and the plastic properties of polycrystalline of pure metals. Philosophical Magazine, 45, 823-843.

40. Sumnar, D. R., Turner, T. M., Igloria, R., Urban, R. M., \& Galante, J. O. (1998). Functional adaptation and ingrowth of bone vary as a function of hip implant stiffness. Journal of Biomechanics, 31(10), 909-917.

41. Sumner, D. R., \& Galante, J. O. (1992). Determinants of Stress Shielding: Design vs Materials vs Interface. Clinical Orthopaedics and Related Research, 274, 202-212.

42. Sundman, B., Jansson, B., \& Andersson, J.-O. (1985). The ThermoCalc databank system. Calphad, 9(2), 153-190.

43. Wang, B., Ruan, W., Liu, J., Zhang, T., Yang, H., \& J, R. (2018). Microstructure, mechanical properties, and preliminary biocompatibility evaluation of binary $\mathrm{Ti}-\mathrm{Zr}$ alloys for dental applications. Journal of Biomaterials Applications, 33(6), 766-775.

44. Wang, X., Zhang, L., Guo, Z., Jiang, Y., Tao, X., \& Liu, L. (2016). Study of low-modulus biomedical $\beta$ Ti-Nb-Zr alloys based on singlecrystal elastic constants modeling. Journal of the mechanical behavior of biomedical materials, 62, 310-318.

45. WolframResearch. (2021, May 24). Mathematica's ElementData. Retrieved from https://periodictable.com/Properties/A/ AtomicRadius.v.html

46. Yang, J., Baatarsukh, M., Bae, J., Huh, S., Jeong, H., Choi, B., . . Noh, J. (2018). Phase stability and properties of Ti-Nb-Zr thin films and their dependence on $\mathrm{Zr}$ addition. Materials, 11, 1-9.

47. Zener, C. (1948). Elasticity and Anelasticity of Metals. Chicago: University of Chicago Press. 